\title{
A Theory of the Firm's Demand for HRM Practices
}

\author{
Bruce E. Kaufman \\ Department of Economics and W.T. Beebe Institute \\ of Personnel \& Employment Relations \\ Georgia State University \\ Atlanta GA USA \\ and \\ Research Fellow \\ Centre for Work, Organization, and Wellbeing \\ Griffith University \\ Brisbane, Qld AU
}

September 17, 2009

bkaufman@gsu.edu

Keywords: human resource management theory; strategic human resource management; economics of personnel 


\section{A Theory of the Firm's Demand for HRM Practices}

Empirical data are presented that reveal a large variation in the pattern of HRM practice adoption across firms. The paper then develops an economics-based theory that explains this pattern. The model broadens the HRM concept; models the linkage between HRM practices and firm performance (the "black box"); generates an HRM input demand function and demand curve; formalizes the concept of strategic HRM; suggests a new empirical tool for HRM research; generates new hypotheses and insights on the nature of the HRM-firm performance relationship; suggests that existing theories of the HRM-firm performance relationship are seriously mis-specified; and posits that on theoretical grounds the effect of more HRM on firm performance in long-run competitive equilibrium is not positive but zero.

\section{Introduction}

The most important and attention-getting line of research over the last twenty years in human resource management (HRM) has been on the relationship between an organization's choice of HRM practices and its operational and financial performance

(Becker and Huselid, 2006; Boxall and Purcell, 2008). Although this literature has greatly enriched and strengthened the HRM field, I argue that serious problems remain. The object of this paper is to point out these problems and then develop a theoretical framework that improves the situation. Specifically, I argue that the mainstream of human resource management theory - represented particularly in the American-based and inspired strategic human resource management (SHRM) literature -- suffers from limited domain and specification error, leading to biased predictions about an organization's best choice of HRM practices. The theoretical framework developed to overcome these problems comes from the standard microeconomic theory of production. The chief conceptual innovation is to treat HRM practices as an input into production and then derive an HRM demand curve and HRM demand function. These tools yield new hypotheses and insights about firms' choice of HRM practices, explain why use of zero- 
to-few HRM policies or practices may nonetheless optimize firm’s performance (i.e., be “best practice”), and provide a new estimating framework for empirical research.

Notably, this model suggests the standard hypothesis in the SHRM literature - that is, "more advanced HRM $\rightarrow$ higher firm performance" -- is seriously inaccurate and comes from a poorly specified and normatively biased model of firm behavior.

\section{HRM facts and theory}

Every field that purports to be a science takes as its main task the identification and testing of causal "if A then B" relationships. Although the personnel/HRM field has for many years been largely applied and problem-driven, since the early-to-mid 1990s HRM scholars have devoted much effort to putting it on a firmer scientific (“analytical”) basis. In particular, numerous articles and books have appeared that in some way endeavor to discover and elaborate the causal relationships that guide firms in their choice of both individual human resource practices and systems (bundles) of such practices. In this spirit, Boxall, Purcell and Wright (2007: 4) state: “The primary task of analytical HRM is to build theory and gather empirical data in order to account for the way management actually behaves in organizing work and managing people across different jobs, workplaces, companies, industries, and societies." The "way management actually behaves" are later called "outcomes" by these authors (the B in the "if A then B" statement), and they assert (p. 6): “analytical HRM....is concerned with assessing outcomes.”

We may next ask: what outcomes are the central facts that the science of HRM seeks to explain? Boselie, Dietz and Boon (2005: 67) provide this answer: "The study of 
HRM is, in its broadest sense, concerned with the selections that organizations make from the myriad policies, practices, and structures for managing employees.” There may be other and perhaps superior ways to analytically represent this statement, but the best known to me is represented in Figure 1.

\section{[Insert Figure 1 here]}

Figure 1 shows two representative HRM frequency distributions. Both are for American firms. A broadly similar bell-shaped pattern (but with much less skewness) has been found for British firms (Bryson, Gomez, and Kretchmer, 2005).

Panel (a) comes from a nationally representative survey of over two thousand workers conducted by Freeman and Rogers (1999). The respondents were asked whether their organization currently used each of ten different HRM practices, including several items usually considered "best practice” (e.g., an employee involvement program, a formal dispute resolution system). Freeman and Rogers combined the ten items into a composite index number and called it a measure of "advanced human-resource practices.” Graphing the data yields the distribution shown in panel (a).

Panel (b) comes from data collected by the Bureau of National Affairs (BNA) in two surveys of several hundred firms (or divisions thereof) in the years 2005 and 2006, respectively. The diagram uses data combined from both surveys, but with duplicates dropped to avoid double-counting. Rather than a count of practices, the BNA data gives a measure of each organization's HRM expenditure per employee (“per capita”). A per capita measure gives a more reliable indicator of cross-firm variation in HRM intensity than total HRM expenditure since the latter is highly correlated with firm size. Both the BNA and Freeman-Rodgers surveys include firms as small as 25 employees. 
Both panels (a) and (b) tell roughly the same story. That is, both HRM frequency distributions resemble a bell-shaped curve but with considerable skewness in the righthand tail. Looking at panel (a), a significant minority of firms, located in the left-hand tail, used very few or even none of the ten formal HRM practices. Perhaps most revealing, nearly one-third of workers said their firm did not even have a formally organized personnel/HR department. The majority of firms in this sample used an intermediate number of HRM practices, while a relatively small proportion of firms utilized many advanced practices and therefore located in the extended right-hand tail. The same dispersion and skewness is shown in panel (b). For example, the median HRM expenditure per employee is $\$ 932$ but 4.5 percent of firms (the "HRM intensive” firms) spent more than $\$ 4,000$ per capita.

In accord with Boselie, Dietz and Boon’s perspective, I put forward the proposition that the central empirical fact to be explained by analytical HRM is the nature of the HRM frequency distribution: that is, its shape at a point in time; change over time; variation across industries and nations; the location of each organization within the frequency distribution; and the composition of and relationship between the individual HRM practices that comprise the organization's chosen HRM package.

The last two decades of analytical HRM research has not been explicitly oriented around the HRM frequency distribution; indeed, I am not aware that this idea has been previously put forward. But this idea is, de facto, clearly present in the mainline of recent theoretical and empirical HRM research and, indeed, can be said to represent the core of the SHRM theoretical and empirical research program. By all accounts (e.g., Becker and Huselid, 2006; Allen and Wright, 2007; Boxall and Macky, 2009), the largest and most 
attention-getting area of HRM/SHRM research concerns the "HRM-firm performance" relationship. What this research stream endeavors to do, in effect, is to predict where on the frequency distribution firms will locate in order to optimize their performance.

The HRM-firm performance literature, both at a theory and empirical level, has been refined and developed along a number of dimensions and has over the last twenty years led to a large and burgeoning literature (see Combs, Liu, Hall, and Ketchen, 2006; Boxall and Purcell, 2008). I argue, however, that on closer inspection this research stream continues to suffer from significant problems of limited domain and mis-specification.

Here, in a nutshell, is the problem. The analytical challenge is to explain why firms adopt the HRM practices they do. The bulk of management researchers argue that firms should choose a particular configuration or "architecture" of HRM practices in order to optimize firm performance -- with some allowance for variation in specific/detailed HRM practices within this architecture (Becker and Huselid, 2006). Conceptually, the range of HRM practice adoption that maximizes organizational performance can range from very low to very high. For a variety of reasons, however, these researchers -- particularly from American universities and in the mainline of the SHRM literature -- have endeavored to demonstrate that theory and empirical evidence both point to the superiority of one particular configuration of HRM practices. This particular HRM bundle is located toward the right-hand tail of the HRM frequency distribution; is envisioned as a set of complementary HRM practices that form a distinct and synergistic employment system; is typically associated with a high involvement and human capital intensive production system and a unitarist employment relation; and typically includes a strategically involved and aligned human resource (HR) department. 
This employment system is most often called a high performance work system (HPWS) utilizing "high performance work practices” (HPWPs). Its key feature is an intensive utilization of formal HRM practices, thus leading to the most important hypothesis in the literature: greater use of "advanced" HRM practices leads to higher organizational performance - on average and giving due allowance to various contingent factors. Given that many (but not all) writers assert that what distinguishes modern HRM from traditional personnel management and industrial relations is that HRM takes a strategic, human capital and "high involvement" approach to people management (Beer and Spector, 1984; Dulebohn, Ferris, and Stodd, 1995), one can say in this version that HRM and “advanced” HRM are roughly equivalent and hence the SHRM field's fundamental proposition can be restated and simplified as: more HRM $\rightarrow$ higher firm performance. This hypothesized relation is typically called the main effect in empirical models and the contingent factors are portrayed as secondary moderator variables (Huselid, 1995).

Regarding the priority given to the HPWS employment system, Marchington and Zagelmeyer (2005: 4) state, "While it is rare to state this explicitly, most studies looking at the HRM-firm performance linkage use some variant of the high performance model;” an observation Purcell and Kinnie (2007: 538) echo when they note, "The lists [of independent variables] appear to emerge from sets of practices normally associated with activities undertaken by well-staffed, sophisticated HR departments in large firms often linked to so-called 'transformational' approaches to the management of labor." Regarding the "more HRM is better" hypothesis, Huselid (1995: 644, emphasis added) states “All else being equal, the use of High Performance Work Practices and good 
internal fit should lead to positive outcomes for all types of firms," while Boselie, Dietz and Boon (2005: 67, emphasis added) note, "[T]he search for a conclusive evidence of the decisive positive impact of the former on the latter [HRM on performance], is for many the whole subject area’s 'Holy Grail’.”

The theoretical components used to develop the "more HRM is better" hypothesis come, most importantly, from the resource-based view (RBV) of the firm and a universalistic "best practice" view of people management practices. The former argues that an organization's human resources (people) are a potential long-run source of inimitable competitive advantage; the latter argues that certain HRM practices are always superior for performance. These components are combined into a model of SHRM, but as noted above with provision for the effect of other contingent external and internal factors. Indeed, these contingencies are getting increased attention in the literature and doubts about the core version of the universalistic model are now being increasingly voiced (Boxall and Macky, 2009). Nonetheless, this opinion shift has not so far caused most HRM researchers to abandon the high performance hypothesis; rather, they continue to posit a positive main effect but now make greater allowance for quantitative variability in its size across firms and in the relative importance of individual HRM practices within the overall high performance architecture. This model has been called a case of "weak contingency" - that is, an hypothesized positive main effect but moderated by contingent factors (Kaufman, 2010b).

Testimony on this point comes from a variety of sources. For example, Legge (2005) reviews the HRM-firm performance theoretical literature and concludes, "The greatest support appears to be for the universalistic model” (p. 231). In the same vein, 
Combs, Liu, Hall and Ketchen (2006) perform a meta-analysis of ninety-two empirical HRM-firm performance studies and, based on their review of the literature, put forward as Hypothesis 1: "The use of HPWPs is positively related to organizational performance.” Becker and Huselid (2006) also provide what appears to be compelling evidence of a positive and quantitatively large "main effect" when they note, "the effect of a one standard deviation change in the HR system is $10-20 \%$ of a firm's market value" (p. 907).

The theory just reviewed provides a basis for a "more HRM $\rightarrow$ higher performance" prediction; nonetheless, a reader of this literature soon realizes it is also driven by distinctly normative concerns (Geare, Edgar, and McAndrew, 2006). Although rarely stated in explicit form, SHRM researchers gravitate to RBV theory and a HPWS model in part because these perspectives hold the promise of giving the human resource field higher professional status and larger strategic importance - important considerations for a field that has historically been relatively marginalized and low-status in both the academic and practitioner worlds. Ferris et. al. (2004: 100) remark, for example, "both HRM researchers and professionals have the potential to underscore the importance of HRM by highlighting its importance to organizational performance;” Wright, Dunford and Snell (2001: 72) similarly note that, "Growing acceptance of internal resources as sources of competitive advantage brought legitimacy to HR's assertion that people are strategically important to firm success.”

Further complicating the matter, SHRM theory is not only normative but also ethnocentric (Brewster, 2004; Wasti, Poell, and Çakar, (2008). The theory originated in America and pertains most closely to an American-style employment system where 
management choice is least constrained by government regulation, union contracts, and social norms. Practices considered "high involvement" in America (e.g., a formal employee council or dispute resolution system) are conventional in medium-large European firms because they are mandated by law (Boxall and Macky, 2009).

In summary, the most frequently cited and utilized theoretical literature in the HRM field predicts that firms either are currently located toward the right-hand tail of the HRM frequency distribution or should be migrating in that direction. This poses a huge empirical challenge, however, for Figure 1 reveals a very wide dispersion in the bundles of HRM practices used at these firms and, furthermore, many firms appear to have adopted "low involvement" and "bare bones" types of employment systems (e.g., the thirty percent of firms without a personnel/HR department). Observation reveals the same pattern in the employment practices of firms in any large metropolitan area, or across different countries (Gooderham, Parry, and Rigdal, 2008). In addition, I also note that historical evidence reveals this large dispersion in HRM practices has existed for many decades (Baron, Dobbin, and Jennings, 1988; Kaufman, 2008, 2010a). Therefore, we come to one of two possibilities. The first is that the predictions of existing SHRM theory are broadly correct but the movement of many firms toward the right-hand tail is blocked by very large transition costs, organizational inertia, and/or managerial ignorance, in effect creating a very large and persistent disequilibrium situation. The second -- the explanation I find more likely - is that the existing mainline of SHRM theory is misspecified and restricted to the upper part of the HRM frequency distribution, consequently yielding skewed and inaccurate predictions (also see Kaufman, 2010b). 


\section{An alternative theory of firms' HRM choice}

Critique is helpful, but even more helpful is providing an improved alternative. Toward this end, I outline in this section an alternative theory that provides a framework for thinking about firms' choices of HRM practices and a testable set of hypotheses about the various features of the HRM frequency distribution. The focus is on for-profit firms, although it would be surprising if most of the implications and hypotheses did not also carry-over to non-profit organizations.

Before beginning, a caveat is in order. This model comes from standard microeconomics, is an application of well-known principles, depicts human resource management in relatively abstract and simplified terms, and speaks to this subject in a different disciplinary language than is common in SHRM. One or more of these features may be problematic for some readers. On the benefit side, the model provides a new way of thinking about firms' choice of HRM practices (it is new even to the "economics of personnel” literature); is able to give a parsimonious yet insightful explanation of the various characteristics of the HRM frequency distribution; yields new hypotheses, research strategies, and empirical tools; and shows why other HRM theories are incomplete or mis-specified. It is also not entirely foreign to the HRM literature, as certain of the modeling ideas and insights were broached a number of years ago by Jones and Wright (1992) and certain findings and conclusions are broached by other authors (e.g., Becker and Huselid, 2006; Subramony, 2006; Boxall and Macky, 2009).

The empirical feature to be explained is the HRM frequency distribution, the firm’s place in it, and its choice of HRM practices both individually and as a package. Since HRM practices are, in effect, the dependent variable, we must be clear on how this 
construct is defined. The definition given by Wright, Dunford and Snell (2001: 703) is "those HRM tools used to manage the human capital pool.” Here arises a conundrum. Most studies, such as in the HRM-firm performance literature, narrow the concept of HRM practices to those that are formal, tangible, or measureable (e.g., Table 1 in Huselid, 1995). This may be a matter of practical necessity in empirical studies but it also mis-specifies the HRM construct, at least broadly considered. As most writers recognize (e.g., Boxall and Purcell, 2008), human resource management is a generic activity that takes place whenever in an organization a person coordinates and directs the labor of another in the process of making a good or service. So defined, it is evident that HRM may be done with no formal, tangible or measurable HRM practice, as takes place today when an employer personally and informally conducts labor management in a small firm (Marlow, 2006) or a century ago when in large firms foremen and supervisors conducted labor management with barely a trace of formal policies or practices (Gospel, 1992; Kaufman, 2008, 2010a). The upshot is that the model I develop here, and implicitly the model used in most of the HRM-firm performance literature, is a partial model in that it seeks to explain only one part of the HRM activity - the firm's decision to invest in a tangible, formal, measurable method of conducting employee management.

In developing the model, therefore, I look at HRM as a generic labor coordination function that organizations use in order to increase their output (Q) of goods and services. Thus, HRM is viewed here as a factor input: an input with a potential benefit - higher productivity and profit - but also a cost - the expense of the labor, capital and intermediate goods needed to produce the labor coordination. To proceed, I dichotomize HRM into two categories: the group of HRM activities that are informal/intangible and 
often delivered by employers and line managers as a part of their overall managerial responsibilities, and the group of HRM activities that are formal/tangible and frequently (but not always) delivered by a personnel/HR department. The first part of HRM is produced by the factor input Labor (L), where L subsumes the total work hours devoted to production by all level of employees, including managers who devote part of their time to the generic activity of labor coordination. The second part of human resource management is produced by the factor input variable HRM, where HRM represents all formal/tangible/measureable aspects of the labor coordination function, such as specialized hiring staff, job evaluation, an employee handbook, annual performance appraisals, and a formalized system of pay grades. This part of the HRM activity is what is captured in Figure 1 and is used in empirical HRM-firm performance studies.

The output of the firm is, accordingly, given by the production function:

$$
\text { 1. } Q=f(K, L, H R M)
$$

where $\mathrm{K}$ represents the factor input capital and $\mathrm{L}$ and HRM are as previously defined. The input $\mathrm{L}$ is measured in work hours; the inputs $\mathrm{K}$ and HRM represent diverse objects (machines and buildings in the first case, practices and programs in the latter) and hence have to be converted into dollars so the individual items can be summed into an aggregate measure for use in the production function. Henceforth, therefore, HRM measures the quantity of tangible/formal labor coordination activities converted to the common denominator of dollars.

The production function in equation 1 needs to be further modified, however, to better capture the effect of HRM on firm performance. This subject is much debated in the literature and remains somewhat murky (Becker and Huselid, 2006; Boxall and 
Purcell, 2008). Emblematically, researchers commonly call the link between HRM and firm performance the "black box." Obviously, the full range of factors in the HRMperformance link cannot be captured in a mathematical model; given this, a dichotomization can nonetheless be made that is both analytically useful and insightful. The dichotomization distinguishes between the direct HRM effect on performance and the indirect HRM effect (Kaufman, 2004a, 2010c). This is represented in equation 2:

2. $Q=f[K, e(H R M) \cdot L, H R M]$

The direct HRM effect represents the independent contribution that more units of an HRM practice (represented by the right-hand term in the production function) has on output, holding constant the amount of labor and capital services. For example, more expenditure on employee selection, such as greater investment in hiring tests, personal interviews, and psychological assessment, will presumably increase output independent of any change in the quantity of labor (e.g., through better matching of people to jobs). Alternatively, extra expenditure on workplace safety may increase Q by reducing workplace accidents and production downtime, while a just-cause termination policy will reduce turnover and increase $\mathrm{Q}$.

The second channel by which additional inputs of HRM affect production is the indirect HRM effect (the middle tern). The indirect effect captures the influence that more HRM practices have on output as they indirectly change the effective amount of labor, through factors such as improved motivation, greater work effort, better citizenship behavior, and skills upgrading. The attempt here is to incorporate channels in the HRperformance linkage suggested by, among others, human capital and what is often called 
“AMO” (abilities, motivation, opportunity) theory (Appelbaum, et. al. 2000; Boxall and Purcell, 2008).

Analytically, the first revision of equation 1 is to expand the labor term from $L$ to L·e . This effectively transforms labor from a commodity input (like a machine) to a human input. The L term is the number of persons/hours of labor; the term e represents what Appelbaum et. al. (2000) refer to as “effective labor.” It is very broadly defined to include the positive effect of more HRM on motivation, effort and skill-upgrading (training/learning). If e $=0$ (e.g., workers sleep all day on the job or have zero skills for the job), then $\mathrm{L} \cdot \mathrm{e}=0$ and no output is forthcoming from the production function; the higher is e, on the other hand, the more effective labor the organization gets from each worker and the more output is produced.

The second revision makes the amount of effective labor $L \cdot e$ a function of the level of HRM practices; that is, $\mathrm{L} \cdot \mathrm{e}(\mathrm{HRM})$. The idea is that HRM practices may contribute to increased "effective labor" either by boosting motivation and effort (e.g., the positive effect on morale from an employee involvement program or a professionallydesigned pay system that promotes fairness through objective standards and hard work through contingent rewards) or by increasing workers' skills, knowledge and abilities (e.g., a training program, sharing of financial and operating information, or internal promotion system).

The choice problem for the firm is to select the level of HRM practices that best achieves it performance objective(s) and for which it has choice (i.e., are not otherwise mandated by law or collective agreements). While firms have numerous goals (Boxall, 2007), certainly in the long-run (and outside the public sector) profit has to take 
precedence if the organization is to survive and grow. Hence, as an analytic simplification I assume the goal of the organization is maximum profit. Given, this the firm's challenge is solve equation 3:

3. $\Pi=\mathrm{P} \bullet \mathrm{f}[\mathrm{K}, \mathrm{e}(\mathrm{HRM}) \cdot \mathrm{L}, \mathrm{HRM}]-\mathrm{V} \cdot \mathrm{HRM}-\mathrm{W} \cdot \mathrm{L}$.

Equation 3 states that profit $(\Pi)$ is the difference between revenue and cost. Revenue is $\mathrm{P} \cdot \mathrm{Q}$, with the production function in equation 2 substituted for $\mathrm{Q}$. Assuming capital is fixed in the short-run, there are two elements of variable cost: labor cost and the cost of HRM practices. Assuming the cost of labor per unit is the wage W (for all employees, including managers, and including benefits and other such costs), total labor cost is $\mathrm{W} \cdot \mathrm{L}$. The HRM practices also have an explicit cost, denoted by V, since they are themselves produced with capital and labor. The total cost of HRM is, therefore, V·HRM (price times quantity). Although the wage $\mathrm{W}$ is, generically viewed, a component of a firm's HRM package, the choice problem considered here is the optimal level of management "manufactured" HRM, so W and V are separately distinguished. Just as the price of labor (W) is assumed a "given" for this exercise (set by the market), so too is the cost of purchasing/producing extra HRM practices (V). This considerably simplifies the model, does not materially affect the results, and broadly accords with reality (e.g., a firm can obtain additional trainers, job evaluations, payroll processing, etc. at a going market price).

The optimal level of HRM is determined by differentiating equation 3 with respect to HRM and solving for the first order condition. This is done in equation 4:

4. $\frac{\partial \Pi}{\partial H R M}=P\left[\left(\frac{\partial Q}{\partial e} \frac{d e}{d H R M}\right) L+\frac{\partial Q}{\partial H R M}\right]=V$ 
The left-hand side of the first-order condition (the bracketed term) is the marginal revenue product (MRP) of HRM practices. It is composed of two parts: the second term captures the direct HRM effect (the effect of more HRM on Q, holding constant L) and the first term captures the indirect HRM effect (the effect of more HRM on Q as it creates more "effective" labor). If labor were a commodity (i.e., inanimate factor input), the term e(HRM) becomes a constant and falls out of the first order condition, leaving only the direct effect. If only the direct effect were present, human resource management would not be substantively different from operations management or an early version of scientific management.

The right-hand side of equation 4 is the unit price of HRM services V. In words, equation 4 is an example of the classic marginal decision-rule found throughout economics: the firm should keep investing additional money in HRM practices (an HR department, job evaluation, employee involvement, etc.) as long as the extra revenue created exceeds the extra cost incurred; when the two become equal the optimal level of HRM practices has been reached (Jones and Wright, 1992).

The data in Figure 1 shows that some firms invest little or nothing in HRM practices, while others invest in an intermediate level and others in a high level. This theoretical model provides an explanation. Each firm, using equation 4, compares the extra productivity and revenue generated by using an additional unit of HRM practice in production with the extra cost incurred. Some firms, given their size, technology of production, skill and demographic characteristics of the workforce, and other such factors (spelled-out in more detail below), find that profits are maximized with zero HRM practices. This might be an "externalized" or "market” type employment system, as 
described by Delery and Doty (1996, Table 1), where demand and supply set pay rates, motivate employees (through threat of unemployment), and provide new recruits and training opportunities. Others find that profits are maximized with an intermediate level, and yet others find, given their size, technology of production and other internal and external characteristics, that a high level of HRM practices maximizes profit. Examples are an HPWS, “high involvement,” and “internal” employment system (again see Delery and Doty, 1996, Table 1).

The first implication of this model, accordingly, is the following: each firm's place in the HRM frequency distribution is determined by a comparison of benefits versus costs of additional investment in HRM practices. For some firms, this calculation yields a zero level of investment in (formal) HRM practices while for others it yields an HPWS.

A second implication concerns the definition of "best practice” HRM. In this framework, one cannot make a universalistic statement that best practice HRM is composed of some particular set of HRM practices, or that best practice is represented by an "HRM intensive" employment system located toward the right-hand tail of the frequency distribution, such as an HPWS. Rather, in this framework "best practice” has only one meaning and metric - that is, the HRM practice (or set of practices) that leads to the most profit (highest financial performance) for the company. Thus, in some situations an HPWS may be best practice, while in others a low road sweatshop employment system may be best practice (Lewin, 2001). One hundred years ago in America and Britain, “best practice” meant next-to-zero formal HRM practices, as it does today in many less-developed countries. 
A third implication concerns the predicted change in the HRM frequency distribution. The maintained hypothesis in most theoretical and empirical studies is that more HRM practices (on average) are associated with higher firm performance. Since the large majority of firms use only an intermediate or small amount of HRM practices (as in Figure 1), this implies that they are foregoing profit. Indeed, if Becker and Huselid (2006) are correct that a one standard deviation increase in HRM practices can add 10\%$20 \%$ to a firm's market value, then these firms are potentially leaving a huge amount of money on the table. In effect, these firms are in a very large disequilibrium situation and, hence, have large incentives to migrate over time toward the more HRM, causing the HRM frequency distribution to gradually narrow until it is centered around some HPWS type employment system. One challenge this theory faces is that there is little evidence that the frequency distribution has in fact perceptibly narrowed over time or that there is a convergence of firms toward the HPWS model; indeed over the last two decades corporate cost-cutting and downsizing appear on balance to have significantly moved firms in the opposite direction as they dismantle internal labor markets and externalize/outsource HRM (Cappelli, et. al. 1997). To explain this discrepant result, Pfeffer (1998: 29) has advanced the “one-eighth” rule, stating that while all (or most all) firms would be higher performing if they adopted an HPWS type employment system that only one-eight actually do so because of organizational inertia, managerial ignorance, and the large costs and obstacles to change.

The model presented here provides a largely opposite interpretation and prediction. This model predicts that the HRM frequency distribution in Figure 1 is a representation, not of a huge disequilibrium, but of an approximate equilibrium. That is, 
the presumption is that firms have solved equation 4 and chosen their spot in the frequency distribution, hence if they are in the middle or lower part of Figure 1 this is their (approximate) best practice position and one they have no incentive to change, other things equal. The fact they do not adopt and HPWS and move to the right-hand tail is not because of ignorance or inertia but something far more fundamental - it does not pay.

Realistically, in an environment of bounded rationality, rapidly changing environmental conditions, organizational politics and inertia, and significant fixed costs it is certainly likely that firms cannot instantaneously move to a new equilibrium position. This creates the possibility that firms are not at their best practice point and, hence, they have a continued need for management consultants and strategic HRM analysis. To avoid straw men and unproductive debates, therefore, the point of contention drawn here may be more broadly framed as a question of degree - i.e., is the extent of disequilibrium and departure from best practice a modest-sized gap that is substantially reduced in a relatively short time period (the economics perspective) or, alternatively, is the gap substantial, widespread, and relatively persistent (the SHRM perspective)?

\section{The HRM demand curve and HRM demand function}

Extensions of the model yield yet further insights and implications, as well as a new tool for empirical HRM analysis. The place to start is derivation of the HRM demand curve.

[Insert Figure 2 here]

This curve depicts the relationship between the price of HRM (V) and the firm's quantity demanded of HRM practices, holding all other factors constant. Such a curve is 
depicted in Figure 2 as $D_{1}$. This curve is derived by plotting the marginal revenue product of HRM. In words, the MRP is the extra dollars of revenue gained from investing in one more unit of HRM practices. The MRP schedule (analytically, given by the bracketed part of equation 4) could initially have an upward sloping portion (not shown here for simplicity of exposition), but eventually will slope downward, given operation of the law of diminishing returns. The common sense of the downward slope is that beyond some point additional investment in HRM practices, such as additional hours of training or additional sophistication in selection tests, has a successively smaller positive effect on productivity and revenue.

Assuming the price of HRM practices is a constant $\mathrm{V}_{1}$ (i.e., just as every other input price is parametric or a "given" for an individual firm in a competitive market), the profit-maximizing level of $\mathrm{HRM}$ practices is $\mathrm{HRM}_{1}$ (point $\mathrm{A}$ ). It is at this point that the equilibrium condition in equation 4 is satisfied; anywhere to the left the MRP of HRM exceeds the marginal cost and the firm adds to profit by expanding expenditure on HRM practices, anywhere to the right the opposite holds true.

Figure 2 shows that a firm's use of HRM practices follows the law of demand, just as does its use of other factor inputs. Thus, a rise in the price of an HRM activity from $\mathrm{V}_{1}$ to $V_{2}$ causes a movement up the HRM demand curve $D_{1}$ and a decline in quantity demanded from $\mathrm{HRM}_{1}$ to $\mathrm{HRM}_{3}$ (point A to point B). If an occupational licensing law were passed, for example, that requires all HRM practitioners to have a university master's degree, firms would have to pay a higher wage (salary) to attract these more educated workers. This higher labor cost would in turn increase the marginal cost of each 
unit of employee recruitment activity, or other such HRM input, leading to a movement up the HRM demand curve and a decline in the firm's quantity demanded.

A firm's demand for HRM practices is also influenced by all those variables that shift the HRM demand curve. These variables must affect one of the two determinants of the HRM input's marginal revenue product: the marginal physical product (the extra output produced) or the marginal revenue from this extra production (or both). Theory suggests a number of these shift variables; others are more a matter of common sense observation or empirical determination (described shortly).

Before proceeding further, it is useful to repackage equation 4 into a more tractable format. This is done in equation 5.

5. $\mathrm{HRM}_{\mathrm{i}}=\mathrm{f}\left(\mathrm{Q}_{\mathrm{i}}, \mathrm{W}_{\mathrm{i}}, \mathrm{V}_{\mathrm{i}}, \mathrm{X}_{\mathrm{i}}\right)$

Equation 5, in effect, inverts the profit maximization equation in equation 4 and expresses the demand for HRM at the $\mathrm{i}^{\text {th }}$ firm as a function of its level of output, the prices of its factor inputs, and a host of other independent variables captured in the vector $\mathrm{X}_{\mathrm{i}}$. Equation 5 can be called the HRM demand function. It parallels the labor demand function, which is a staple of labor economics (Hamermesh, 1993). Holding all other variables constant, changing the level of $\mathrm{V}$ in equation 5 causes a movement along the HRM demand curve $\mathrm{D}_{1}$ in Figure 2; holding $\mathrm{V}$ constant and changing one of the other variables in the demand function (e.g., larger or smaller scale of output) shifts the HRM demand curve to the right $\left(D_{2}\right)$ or left $\left(D_{3}\right)$, respectively. At a constant price of $V_{1}$, a rightward shift of the firm's demand for HRM practices leads to an increase in use of HRM practices from $\mathrm{HRM}_{1}$ to $\mathrm{HRM}_{2}$ (point A to point C); a leftward shift reduces $\mathrm{HRM}$ practices from $\mathrm{HRM}_{1}$ to $\mathrm{HRM}_{3}$ (point A to E). 
More implications emerge. For example, the HRM demand curve and demand function model provides an interesting explanation for the shape of the HRM frequency distribution at a point in time and for changes in it over time. At a point in time, each firm has particular values of the variables $\mathrm{V}, \mathrm{W}$ and the $\mathrm{X}$, and, inserting these into the demand function, yields its optimal level of HRM practices. Plotting these equilibrium values traces-out the HRM frequency distribution, as in Figure 1. Alternatively, one can plot the position of firms' HRM demand curves in Figure 2 and, for a given price (e.g., $V_{1}$ ), determine the same distribution of equilibrium values of the HRM practice variable. In effect, the distribution of HRM demand curves maps-out an identical frequency distribution of HRM practices. Thus, the left-hand tail of the HRM frequency distribution is described by the one-third or so of firms that have a zero-to-small demand for HRM (e.g., demand curves to the left of $\mathrm{D}_{3}$ ), the center of the distribution is given by the majority of firms that have "intermediate" HRM demand curves (in a band around $\mathrm{D}_{1}$ ), and the skewed part of the right-hand tail is given by the relatively small number firms that have a very high demand for HRM (demand curves scattered far to the right of $\mathrm{D}_{2}$ ).

This model also explains changes in the HRM frequency distribution across time and countries. Illustratively, at the turn of the 20the century the HRM frequency distribution was highly compressed and centered very close to the vertical axis (Kaufman, 2008, 2010a). As an example, in 1902 the world's largest company, the United States Steel Corporation, employed 160,000 people but used practically zero formal HRM practices. The reason is that nearly all firms were using a highly externalized labor management system (but possibly still best practice!) and thus had near-zero HRM demand curves. Over the ensuing decades, however, the HRM demand 
curves of many firms shifted successively to the right -- due to changes in production technology, unionization, legal regulation of employment, and other such factors, causing the mean and variance of the HRM frequency distribution to also increase. In recent years, the erosion of internal labor markets may have caused many firms’ HRM demand curves to start shifting left again. Finally, variation in HRM demand curves also explains different HRM frequency distributions among countries, such as between the USA, France and India.

I earlier noted that this model has its shortcomings and problematic aspects (e.g., severe simplification), but the true test of a theory is (a) if it is logically well constructed, (2) has generality beyond a small range of cases, and (3) explains/predicts a phenomenon better than alternative theories. I ask the reader to consider whether there are any other HRM theories that can do better on these three counts with regard to explaining the shape and change therein in the HRM frequency distribution.

Another contribution of this model is that it yields a fruitful tool for empirical analysis, and also reveals a fundamental flaw in the conventional approach. Since the pioneering study of Huselid (1995), the standard empirical approach in the field is to estimate an HRM-firm performance regression with some measure (or list) of HRM practices as an independent variable and a measure of firm performance as the dependent variable. The estimated coefficient on the HRM variable measures the marginal effect of a one unit change in HRM on profit (taking profit, or rate of return in investment, as the performance measure); the maintained hypothesis in the literature, in turn, is that the HRM coefficient is positive and significant. ${ }^{1}$

\footnotetext{
${ }^{1}$ Note that if a different dependent variable is used, such as productivity, the HRM coefficient may be positive yet here is another mis-specification since productivity can increase yet the large expenditure cost
} 
On closer examination, however, the HRM-firm performance specification appears conceptually and statistically problematic. Surely what firms do -- and this is what SHRM counsels them to do -- is they look at HRM as a choice variable and endeavor (however imperfectly) to select the HRM practices that maximize performance. But, then, how in any meaningful sense can the HRM variable be considered an independent determinant of performance? Our model says it cannot be, since the two (HRM and performance) are jointly determined when firms solve equation 4. Instead, the more correct approach is to view the HRM variable as the dependent variable that firms are solving for as a function of all the independent variables that determine the benefits and costs of HRM. But this yields an entirely different estimating equation, which is given by the HRM demand function in equation 5. Thus, I am asserting two things: first, that the last fifteen years of empirical HRM-firm performance studies are likely built on a mis-specified model and, second, that a more fruitful and appropriate tool for empirical investigation is the HRM demand function equation.

Another aspect of mis-specification is the conceptualization of the SHRM construct. For example, Wright and McMahan (1992: 298) in an oft-cited study define SHRM as "[t]he pattern of human resource deployments and activities intended to enable an organization to achieve its goals.” But this definition is nothing but a restatement of the firm's profit maximization decision, as given in equations 3 and 4, and thus appears to lack independent intellectual substance. It also appears to make HRM non-strategic (if SHRM maximizes equations 3 and 4, then HRM must by logic be implemented largely without reference to firm performance), yet many writers assert that what distinguishes do down. 
HRM from traditional personnel management and industrial relations is that the former is strategic but the latter are not (e.g., Dulebohn, Ferris, and Stodd, 1995).

Based on the foregoing, I assert yet another fundamental implication. Not only is the conventional HRM-firm performance equation mis-specified, so most likely is the maintained hypothesis derived from theory (e.g., the RBV) that the HRM coefficient is positive. If firms have chosen their best practice (most profitable) HRM level (call it $\mathrm{HRM}^{*}$ ) via equation 4, any change upward or downward in HRM practices from HRM* necessarily lowers profitability. ${ }^{2}$ Thus, the model predicts that if all firms have adopted their equilibrium $\mathrm{HRM}^{*}$ then the HRM coefficient in a standard HRM-firm performance regression model should be zero. That is, in a situation of long-run competitive equilibrium all firms earn an identical rate of return of capital (e.g., 10\%); hence, variation in HRM across firms (the independent variable) is associated with zero variation in profitability (the dependent variable) so $\Delta$ Performance/ $\Delta \mathrm{HRM}=0$.

However, empirical studies do frequently obtain a significant positive HRM coefficient (Combs, et. al., 2006). Our model implies this may well be due to statistical mis-specification, a non-representative sample (e.g., mostly medium-to-large firms), a short-run disequilibrium situation, a mis-attributed rent arising from some noncompetitive market factor (e.g., heterogeneity in management quality), publication bias, a persistent form of market failure (e.g., under-capitalization of the future profits of more HRM due to the intangible nature of most of the benefits arising through the HRM indirect effect), or the fact an incorrect inference is made about profitability from an

\footnotetext{
${ }^{2}$ When making cross-firm comparisons it is necessary to standardize for firm size, implying dollars of profit should be replaced by a relative measure, such as rate of return on capital. The sign and size of the regression coefficient on the HRM variable differs according to the exact specification of the performance variable.
} 
intermediate performance variable such as turnover or productivity (also see Wall and Wood, 2005; Purcell and Kinnie, 2007; Gerhart, 2007).

Simple economic reasoning leads to the same conclusion. If the HRM coefficient is positive, this implies firms add to profit by increasing their use of HRM. Presumably they will do exactly this (particularly if, as many SHRM studies claim, market competition is intensifying) but, beyond some point, due to the law of diminishing returns the marginal contribution to profit declines until it reaches zero and at which point the incentive for further investment is also zero. Huselid (1995) recognizes this implication of economic theory but nonetheless discounts its empirical significance; most other SHRM authors ignore it altogether.

Nonetheless, it is possible that more HRM does lead in a causal sense to more profit if, as the RBV predicts, high performance HRM practices are able to create economic rents that competitors cannot easily capture. But this explanation faces two challenges that have not yet been fully answered. The first challenge is to explain how more HRM practices create competitive advantage. The indirect effect in equation 4 essentially models this process, but to be convincing the HRM literature needs to provide a more detailed, concrete and empirically supported explanation of how this process works. The second and more difficult part of the story is to explain what prevents other firms from quickly adopting higher performing HRM practices and thus rapidly competing away the rents. Certainly it seems plausible that people can be a source of long-run competitive advantage (Boxall and Macky, 2009). However, the idea that HRM practices - at least the conventional "tools" definition used in the literature -- is a significant source of this competitive advantage is more difficult to argue, given that most 
HRM practices are fairly generic, widely available, and in most cases relatively easy to implement (Boselie, Dietz and Boon, 2005). The possible recourse here, as some have put forward, is to argue either that HRM employment systems entail considerable path dependency or that the sustainable economic rent comes from the much more difficult task of putting together and operating the entire HPWS package (Allen and Wright, 2007). Of course, skeptics (e.g., Delaney and Goddard, 2001) can then point to evidence that effective HPWS employment systems are rather fragile and often have a short halflife.

\section{Independent variables and HRM choice}

If variation in demand curves explains the variation in firm-level HRM practices, then the next step in theorizing is to identify the specific independent variables (shift factors and moderating contingencies) in the HRM demand function that give rise to this variation. Provided below are some of the shift factors that theory and evidence suggest are most important. The first two (Q and $\mathrm{W}$ ) are explicitly identified in equation 5; the remainder are subsumed in the vector $\mathrm{X}$. This list is suggestive and not definitive.

Firm Size. The demand for HRM practices should increase with firm size, measured by level of output (Q) or level of employment (jointly determined by Q and W in eq. 5 and not therefore explicitly shown). This relationship is uniformly found in empirical studies (Boselie, Dietz, and Boon, 2005). A theoretical rationale is that the transaction cost of market governance increases with firm size due to greater difficulty and complexity of coordinating large groups of workers through market controls and incentives. 
Wage Rate. The second variable in the HRM demand function in eq. 5 is the wage rate $\mathrm{W}$. The wage may be either a substitute or complement for HRM practices (Ichniowski, Shaw and Prennushi, 1997). In the former case, firms may use a higher W in lieu of formal HRM practices. An example would be efficiency wage theory where by paying a higher-than-market wage employees are motivated to self-enforce higher work effort and firms can reduce direct HRM control devices, such as supervision and time clocks. In this case, a higher wage would shift the HRM demand curve to the left. The opposite would occur where W and HRM practices are complements. In high performance work systems, for example, a high wage and high level of HRM go together. One reason is that an HPWS requires a unitarist employment relationship and paying a high wage creates higher employee commitment and loyalty and removes a source of potentially disruptive distributive bargaining (tacit or formal).

Firm Age. The demand for HRM practices tends to increase with firm age. The longer-lived are firms, the more they develop rules and bureaucratic procedures to deal with employment policy and problems. Older firms (and plants), however, have more difficulty adopting new HRM practices, particularly as a complete package, implying a contingency between firm age and the type of HRM system (Appelbaum, et. al., 2000).

Production Technology. Internalization of employment is encouraged by production technologies that are more complex, feature greater worker interdependencies (e.g., team forms of production), and allow greater room for discretionary effort. More complex technology makes employee selection more difficult and important and turnover more expensive; more extensive interdependencies in production increase the need to maintain and promote effective employee coordination and cooperation; and greater room 
for discretionary work effort heightens the importance of maintaining/promoting employee commitment and morale (Begin, 1991).

Industry/Organizational Characteristics. HRM demand is likely to vary by industrial and organizational characteristics. Manufacturing firms, for example, may require a more HRM intensive employment system than service firms (Datta, Guthrie, and Wright, 2005). Likewise, on the organization side firms with a greater degree of centralization of operations and management control are more likely to have a larger amount of formal HRM practices in order to maintain and promote consistency and company-wide coordination . Other potentially important organizational characteristics are profit/non-profit status and public/private ownership (Luthans and Sommer, 2005).

Training/Knowledge Characteristics. Internalization of employment and demand for HRM practices will also be greater in firms where production involves greater specific on-the-job training (OJT). Specific OJT creates a form of asset specificity, thus raising market transaction cost. Work systems that provide more opportunity for workers to develop and apply new knowledge for improvements in processes and products will also have a greater demand for HRM practices, per the implications of the resource based view of the firm. Lepak and Snell (1999) call these two characteristics "uniqueness" and "value."

Workforce Characteristics. Firms will have a greater demand for HRM practices the greater the extent to which they obtain labor from, respectively, employees rather than contract/contingent workers, full-time rather than part-time workers, and workers with characteristics (e.g., education, skill) that are associated with higher turnover and 
(internal) training costs. HRM intensity may also vary with the gender and age composition of the workforce.

Economic/Market Conditions. Firms operating in more stable product markets and economic environments have a greater incentive to adopt internal labor markets (ILMs) and formal HRM practices (Orlitzky and Frenkel, 2005). ILMs involve greater employee investment expense, transform labor into a quasi-fixed cost, and introduce greater organizational rigidity. These conditions become progressively less economic in the face of greater volatility of sales and employment and shorter product life-cycles. ILMs and extensive HRM practices are also promoted when labor markets remain at or close to full employment. Not only does full employment increase the pressure to carefully select, develop and retain employees (due to scarcity of qualified labor in the external market), it also reduces the ability of firms to use the threat of unemployment as an effective and less costly motivation/discipline device.

HRM Innovations. The number and sophistication of HRM tools available to firms expands over time due to new discoveries and innovations in HRM organization, methods, and practices. New innovations increase productivity and/or lower cost, thus increasing HRM practice demand.

Unionization. The presence of a union in the firm, or closely competing firms, has potentially offsetting effects on the demand for HRM practices. A union endeavors to negotiate more formalized, structured and standardized employment management practices. A firm with a union must, therefore, invest more in HRM (Verma, 2007). If closely competing firms have a union, or a strong organizing threat otherwise exists, an unorganized firm will also attempt to preserve its non-union status through greater HRM. 
On the other hand, unionization may lead to lower HRM if the union takes over certain functions (e.g., selection and hiring through a hiring hall) or resists certain practices (e.g., profit-sharing).

Government. Greater government regulation of employment heightens the incentive of firms to adopt formal HRM practices in order to comply with government mandates, avoid legal costs, and maintain a positive community image. Firms also practice more extensive HRM in order to forestall the threat of greater government regulation of employment ("government avoidance," akin to union avoidance). On the other hand, these HRM practices - while large in number - may be more "compliance" oriented and not bulk large in dollars of expenditure relative to certain "high involvement” practices (e.g., team training, gain-sharing).

Social/Cultural Factors. Companies create distinct social environments and organizational cultures, some of which promote a demand for HRM practices and others which don't. Companies, for example, that seek to inculcate esprit d'corps, loyalty and egalitarianism will have a greater demand for HRM practices; companies where work is “only a job” or a short-term instrumental relationship will have a smaller demand for HRM. Social and cultural factors can also explain HRM practice variation across nations and, perhaps, regions or ethnic groups (Brewster, 2004). HRM was slower to develop and spread in the UK than the USA, for example, in part because of the British social ethos that in earlier years downgraded professional management and the importance of management education (Gospel, 1992; Kaufman, 2004b). HRM, on the other hand, has been strongly emphasized in Japanese firms, partly because of a social ethos that puts a 
high emphasis on preserving group harmony and long-term employment relationships (Jacoby, Nason, and Saguchi, 2005).

Management Philosophy. Company owners and top executives differ in their philosophies and attitudes toward employees and labor management practices. This factor most closely corresponds to the "taste" variable in the traditional microeconomic theory of demand. Quite apart from profit considerations, some owners/executives take an "employee-oriented" approach as a matter of managerial philosophy and hence tend to put more resources into HRM, while others have a "hired hands" viewpoint and accordingly give HRM little emphasis (Foulkes, 1980; Kaufman, 2010a).

Business Strategy. I put last in the list of shift factors what most HRM researchers would probably put first: the firm's business strategy. Theoretically, however, a legitimate question arises whether a business strategy variable has independent explanatory power in the HRM demand function. That is, business strategy can be thought of at the most basic level as determining the best means to reach given ends (Boxall and Purcell, 2008). Applied to HRM, this naturally leads to Wright and McMahan's definition of SHRM (previously cited). But, as earlier pointed out, in a world of perfect information and competitive markets, "business strategy" is nothing but a restatement of the firm's profit-maximization problem in equation 3 which, when solved, yields the various first order conditions determining product prices, level of output, and the usage and mix of factor inputs (equation 4). If all the relevant variables that affect profits are included in equation 3 and the problem is correctly optimized by business decision-makers, the firm's business strategy (means-ends choice) emerges as the solution of the model - that is, the solution is the strategy. Since the HRM demand 
function in equation 5 is derived from the solution of the model, the predicted value of HRM practices that comes from it already completely reflects and incorporates (via the $\mathrm{Q}, \mathrm{W}, \mathrm{V}$ and $\mathrm{X}$ variables) the firm's choice of business strategy. Vertical fit is thus an outcome of solving the model, while a separate variable in the HRM demand function called "business strategy" becomes redundant and empty of conceptual content.

This conclusion holds, of course, only in the context of the highly artificial and restrictive assumptions of the simple microeconomic model. When the model is modified to incorporate more realistic features, such as bounded rationality, intra-organizational politics, and a variety of market imperfections (e.g., barriers to entry, heterogeneous resources), the concept of business strategy gains independent explanatory power for the firm's means-ends choice is no longer deterministic or obvious. Firms with the same variables in the HRM demand function, therefore, may adopt different business strategies in their quest to maximize profit, yielding in turn different outcomes for the HRM practice variable in equation 5 . One must nevertheless be cautious in the use and interpretation of standard business strategy typologies in the HRM demand function (e.g., "prospector versus defender"), as choice of a particular strategy is presumably itself a function of the other independent variables. To the degree some of these variables are omitted from the HRM demand function, the strategy variable proxies for their influence. These considerations perhaps explain the weak and inconsistent empirical findings regarding the link between business strategy and HRM practices (Becker and Huselid, 2006)

\section{The equilibrium mix of several HRM inputs}


The model has been used to address three fundamental features of the HRM frequency distribution depicted in Figure 1 - the firm's place in the frequency distribution, the shape of the distribution, and changes in the distribution over time and across countries. A fourth important feature remains: the mix or "bundle" of individual HRM practices that comprise each firm's overall position in the distribution. Thus, Freeman and Rogers (1999) found that firms in the right-hand tail of the distribution not only used more HRM practices but also tended to adopt a particular mix of practices, such as employee involvement, formal dispute resolution, and gain-sharing forms of pay. Firms in the lefthand tail, on the other hand, not only invested in a low level of HRM practices but also chose a mix of HRM practices often associated with a "low involvement" or "low road" employment system.

The challenge is to model the process by which firms mix and match individual HRM practices to form an overall HRM system. To begin, one could replace the composite HRM practice variable (HRM) in equations 3 and 4 with a vector of $n$ individual HRM functional practice areas, denoted $\operatorname{HRM}_{\mathrm{i}}(\mathrm{i}=1, \ldots ., \mathrm{n}$; with i now indexing practices and not firms). Thus, $\mathrm{HRM}_{1}=$ selection, $\mathrm{HRM}_{2}=$ training, $\mathrm{HRM}_{3}=$ employee benefits, and so on, with higher values of $\mathrm{HRM}_{\mathrm{i}}$ representing more extensive/intensive deployments. The per-unit cost of input $\mathrm{HRM}_{1}$ is $\mathrm{V}_{1}$, the per-unit cost of input $\mathrm{HRM}_{2}$ is $\mathrm{V}_{2}$, and so on. In a yet more realistic but also complex treatment, one could further decompose the i HRM functional practice areas into $\mathrm{j}(\mathrm{j}=1, \ldots \ldots, \mathrm{m})$ alternative methods. Thus, assume $\mathrm{HRM}_{1}$ stands for selection and $\mathrm{HRM}_{2}$ is training; then $\mathrm{HRM}_{11}$ and $\mathrm{HRM}_{12}$ stand for two specific selection methods (e.g., background checks 
and ability tests) and HRM 21 and $\mathrm{HRM}_{22}$ stand for two methods of training (e.g., on-thejob and classroom training). The individual $\mathrm{HRM}_{\mathrm{i}}$ and $\mathrm{HRM}_{\mathrm{ij}}$ may be complements or substitutes in production, as discussed below.

The first-order condition in equation 4 expands to $\mathrm{n}$ first-order conditions, such as indicated in equations 6:

$$
\text { 6. } \begin{aligned}
\mathrm{V}_{1} & =\mathrm{MRP}_{1} \\
\mathrm{~V}_{2} & =\mathrm{MRP}_{2} \\
& \cdot \\
\mathrm{V}_{\mathrm{n}} & =\mathrm{MRP}_{\mathrm{n}} .
\end{aligned}
$$

Equations 6 states in words that additional units of each individual HRM practice should be committed to production as long as the marginal increase in revenue exceeds the marginal increase in cost.

In much the same way as consumers maximize total utility by equating the marginal utility per dollar spent on each item consumed, firms maximize profit by equating the marginal revenue product per dollar-cost of each input used in the production process. Thus, the equilibrium amount of multiple HRM inputs is given by equation 7:

$$
\text { 7. } \mathrm{MRP}_{1} / \mathrm{V}_{2}=\mathrm{MRP}_{2} / \mathrm{V}_{2} \ldots=\mathrm{MRP}_{\mathrm{n}} / \mathrm{V}_{\mathrm{n}}
$$

This equation states that the firm should adjust the amount of each HRM input until the revenue gain per dollar of expenditure on each is equal. If, ceteris paribus, the MRP of the employee selection function increases (say due to a tighter labor market and greater scarcity of qualified employees), the firm maximizes profit by reallocating HRM expenditures from training to selection. 
An interesting question in HRM research is the extent to which firms mix and match individual HRM practices into a smaller set of identifiable packages or bundles (the “configurational” perspective). Sometimes these bundles are called employment systems. One such bundle, for example, is an HPWS. Several writers have identified up to a half-dozen alternative employment systems, each distinguished by a distinctive set of HRM practices (e.g., Osterman, 1987; Begin, 1991; Marsden, 1999; Barton, Burton, and Hannan, 1999; Toh, Morgeson, and Campion, 2008). Begin, for example, identifies these six systems: simple, machine, professional bureaucracy, adhocracy, missionary and divisional.

The individual HRM practices will cluster together into a smaller set of identifiable systems if the individual $\mathrm{HRM}_{\mathrm{i}}\left(\right.$ and $\mathrm{HRM}_{\mathrm{ij}}$ ) are related to each other in production as complements or substitutes (MacDuffie, 1995; Laursen and Foss, 2003). To measure this relation we must return to the profit function, initially presented in equation 3 but modified below in equation 8 . Equation 8 simplifies the profit function by specifying the labor input as the single variable L, but complicates it by separating the HRM variable into the separate individual HRM practices, $H_{R} M_{i}$.

8. $\Pi=\mathrm{P} \bullet \mathrm{f}\left[\mathrm{K}, \mathrm{L}, \mathrm{HRM}_{\mathrm{i}}\right]-\mathrm{V}_{\mathrm{i}} \cdot \mathrm{HRM}_{\mathrm{i}}-\mathrm{W} \cdot \mathrm{L}$.

The HRM inputs may be independent (separable/additive) in production, or may be related as complements or substitutes. Two HRM practices, such as $\mathrm{HRM}_{1}$ and $\mathrm{HRM}_{2}$, are complements in production if $\delta \Pi^{2} / \delta \mathrm{HRM}_{1} \delta \mathrm{HRM}_{2}>0$ or, in words, if an increase in the usage of one HRM input raises the marginal profit return to the other (Milgrom and Roberts, 1991: 108). This might be the case, for example, if greater expenditure on employee selection increases the return on a given expenditure on employee training 
(perhaps because of a better person/job fit and thus greater productivity in training). Alternatively, HRM inputs may be substitutes in that greater usage of one reduces the marginal profit return to the other (the second derivative of the profit function is negative). An example would be if greater expenditure on employee involvement reduces the return on quality inspection staff. A third possibility is that the HRM inputs are completely separable, making the second derivative zero.

\section{Conclusion}

This paper makes two fundamental contributions to advancing a positive theory of HRM. The first is to identify the major type of empirical phenomenon that a theory of HRM must seek to explain and predict. This phenomenon is the frequency distribution of HRM practices (Figure 1), both among firms (and nations) at a point in time and changes in this distribution over time. Granted, not all HRM theories will have equal applicability to this issue, and certainly other empirical phenomena in HRM also deserve attention, but nonetheless the ability to explain all parts of the HRM frequency distribution, and its major features, surely must stand as a central litmus test for any and all theories in this

field. Based on this standard, I judge that most existing HRM theories are partial, incomplete and biased toward larger firms with formal HR departments, as located in the right-hand tail. Other people have also made this observation but to date the mainline SHRM literature has taken little notice.

The second major contribution of the paper is to develop a new theoretical framework for HRM. This framework, drawing principally from economics, provides a theoretical explanation for the HRM frequency distribution. The central analytical 
construct is an HRM input demand function and demand curve. Although this model is more abstract and mathematical than is common for the HRM field, my claim is that this abstractness and formalism have a large pay-off because they yield a theory with much greater generality and explanatory power. For example, not only can the theory explain the major features of the HRM frequency distribution, it also provides a convenient and insightful framework for structuring empirical work (the HRM input demand function) and provides deeper insight into the conditions under which HRM will (and will not) have a positive effect on firm performance.

Finally, this model also illuminates two fundamentally different strategies for theorizing HRM. The approach adopted here treats the firm's place in the HRM frequency distribution as an equilibrium outcome (or tendency) of deliberative management choice explicable in terms of a rational (or mostly rational) weighing of benefits and costs; the outcome of this process, in turn, is adoption of a "best practice" HRM configuration where "best practice" in some cases may entail few if any formal HRM practices and in other cases a bundle of numerous advanced practices. The approach explicit or implicit in much of the mainline SHRM literature, on the other hand, proceeds largely independent of an economic calculus of benefits and costs of HRM investment and instead uses an amalgam of universalistic, RBV, and contingency principles drawn from the strategic management literature to argue that that most (if not all) firms maximize performance by adopting some variant of an "HRM intensive" employment model (e.g., an HPWS) located toward the right-hand tail of the frequency distribution. Since HRM bundles among real-life firms show substantial dispersion and heterogeneity, the SHRM approach necessarily entails some type of disequilibrium model 
in order to explain the large and persistent gap between what firms actually do and what the theory predicts they should do. Although both modeling strategies have their advantages and disadvantages, I suspect the equilibrium approach used here is not only more analytically tractable but also more productive of insights and testable hypotheses.

*The author wishes to thank Brian Becker and Peter Boxall for helpful comments on an earlier draft of this paper.

\section{References}

Allen, M., and Wright, P. (2007) 'Strategic Management and HRM.' In Boxall, P., Purcell, J., and P. Wright (eds), Oxford Handbook of Human Resource Management. Oxford: Oxford University Press, pp. 88-107

Appelbaum, E., Bailey, T., Berg, P., and Kalleberg, A. (2000) Manufacturing Advantage: Why High-Performance Work Systems Pay Off. Ithaca, NY: Cornell University Press.

Barton, J., Burton, D., and M. Hannan. (1999) ‘The Road Not Taken: Origins and Evolution of Employment Systems in Emerging Companies. In Carroll, G. and 
Teece, D. (eds), Firms, Markets, and Hierarchies. New York: Oxford University Press, pp. 429-64.

Becker, B., and Huselid, M. (2006) 'Strategic Human Resource Management: Where Do We Go From Here?’ Journal of Management, 32: 898-925.

Beer, M., and B. Spector. (1984) 'Human Resources Management: The Integration of Industrial Relations and Organizational Behavior.' In Rowland, K., and G. Ferris (eds), Research in Personnel and Human Resource Management, Vol. 2 Stamford: JAI Press, pp. 261-97.

Begin, J. (1991) Strategic Employment Policy: An Organizational Systems Perspective, Englewood Cliffs, NJ: Prentice-Hall.

Boselie, P., Dietz, G., and Boon, C. (2005) 'Commonalities and Contradictions in HRM and Performance Research,' Human Resource Management Journal, 15: 67-94.

Boxall. P. (2007) ‘The Goals of HRM.’ In Boxall, P., Purcell, J., and P. Wright (eds), Oxford Handbook of Human Resource Management. Oxford: Oxford University Press, pp. 48-67.

Boxall, P. and K. Macky. (2009) 'Research and Theory on High-Performance Work Systems: Progressing the High-Involvement Stream,' Human Resource Management Journal, 19: 3-23.

Boxall, P., and Purcell, J. (2008) Strategy and Human Resource Management, $2^{\text {nd }}$ ed. New York: Palgrave Macmillan.

Brewster, C. (2004) 'European Perspectives on Human Resource Management,' Human Resource Management Review 14: 365-82. 
Bryson, A., Gomez, R., and T. Ktechmer. 2005. 'Catching a Wave: The Adoption of Voice and High-Commitment Workplace Practices in Britain, 1984-1998.' CEP Discussion Paper No. 676. London” Centre for Economic Performance, London School of Economics.

Bureau of National Affairs. (2006) HR Department Benchmarks and Analysis: 2005 -2006. Washington: Bureau of National Affairs.

Coombs, J., Ketchen, D., Hall, A., and Liu, Y. (2006) ‘Do High Performance Work Practices Matter? A Meta-Analysis of Their Effects on Organizational Performance,' Personnel Psychology, 59: 501-528.

Datta, D., Guthrie, J., and P. Wright. (2005) ‘Human Resource Management and Labor Productivity: Does Industry Matter?' Academy of Management Journal, 48: 135 -145 .

Delaney, J. and Goddard, J. (2001) ‘An Industrial Relations Perspective on the High -Performance Paradigm,' Human Resource Management Review, 11: 395-430.

Delery, J. and Doty, D. (1996), 'Modes of Theorizing in Strategic Human Resource Management: Tests of Universalistic, Contingency, and Configurational Performance Predictions,' Academy of Management Journal, 39: 802-835.

Dulebohn, James, Ferris, Gerald, and James Stodd. (1995), ‘The History and Evolution of Human Resource Management.' In Ferris, G., Rosen, S., and D. Barnum (eds), Handbook of Human Resource Management. Cambridge, MA: Blackwell, pp. 19-41.

Foulkes, Fred. (1980) Personnel Policies at Large Nonunion Companies. Englewood Cliffs, NJ: Prentice-Hall. 
Freeman, R., and Rogers, J. (1999) What Workers Want. Ithaca, NY: Cornell University Press.

Geare, A., Edgar, F., and McAndrew, I. (2006) ‘Employment Relationships: Ideology and HRM Practice,' International Journal of Human Resource Management, 17: 1190-1208.

Gerhart, B. (2007) ‘Modeling HRM and Firm Performance Linkages.’ In Boxall, P., Purcell, J., and P. Wright (eds), Oxford Handbook of Human Resource Management. London: Oxford University Press, pp. 552-580.

Gooderham, P., Parry, E., and K. Ringdal. (2008) ‘The Impact of Bundles of Strategic Human Resource Management Practices on the Performance of European Firms,' International Journal of Human Resource Management, 19: 2041-2056.

Gospel, H. (1992), Markets, Firms, and the Management of Labour in Modern Britain. Cambridge: Cambridge University Press.

Huselid, M. (1995) 'The Impact of Human Resource Management Practices on Turnover, Productivity, and Corporate Financial Performance,' Academy of Management Journal, 38: 635-672.

Ichniowski, C., Shaw, K., and Prennushi, G. (1997) 'The Effects of Human Resource Management Practices on Productivity: A Study of Steel Finishing Lines,' American Economic Review, 87: 291-313.

Jacoby, S., Nason, E., and K. Saguchi. (2005), ‘The Role of the Senior HR Executive in Japan and the United States,' Industrial Relations, 44: 207-241.

Jones, G., and Wright, P. (1992) ‘An Economic Approach to Conceptualizing the Utility of Human Resource Management Practices.' In Ferris, G., and K. Rowland (eds), 
Research in Personnel and Human Resource Management. Greenwich, CT: JAI Press, pp. 271-300.

Kaufman, B. (2004a) 'Toward an Integrative Theory of Human Resource Management.' In Kaufman, B. (ed), Theoretical Perspectives on Work and the Employment Relationship. Urbana-Champaign, IL: Labor and Employment Relations Association, pp. 321-366.

Kaufman, B. (2004b) The Global Evolution of Industrial Relations: Events, Ideas, and the IIRA, Geneva: ILO.

Kaufman, B. (2008), Managing the Human Factor: The Early Years of Human Resource Management in American Industry. Ithaca, NY: Cornell University Press.

Kaufman, B. (2010a), Hired Hands or Human Resources? Case Studies of HRM Practices and Programs in Early American Industry. Ithaca, NY: Cornell University Press.

Kaufman, B. (2010b) 'SHRM Theory in the Post-Huselid Era: Why It is Fundamentally Mis-specified,’ Industrial Relations, 49: 286-313.

Kaufman, B. (2010c) ‘The Firm’s Choice of HRM Practices: Economics Meets Strategic Human Resource Management,' Industrial and Labor Relations Review, forthcoming.

Laursen, K., and Foss, N. (2003) 'New Human Resource Management Practices, Complementarities and the Impact on Innovation Performance,' Cambridge Journal of Economics, 27: 243-263. 
Legge, K. (2005) ‘Human Resource Management.’ In Ackroyd, S.., Batt, R., and P. Thompson (eds), The Oxford Handbook of Work and Organization. Oxford: Oxford University Press, pp. 220-241.

Lepak, D., and Snell, S. (1999) 'The Human Resource Architecture: Toward a Theory of Human Capital Allocation and Development,' Academy of Management Review, 24: 31-48.

Lewin, David. (2001) ‘Low Involvement Work Practices and Firm Performance.’ In Proceedings of the $53^{\text {rd }}$ Annual Meeting, Industrial Relations Research Association, Champaign, IL: Industrial Relations Research Association, pp. 275 $-291$.

Luthan, K., and Sommer, S. (2005) 'The Impact of High Performance Work on Industry -Level Outcomes,' Journal of Management Issues, 17: 327-345.

MacDuffie, J. (1995) ‘Human Resource Bundles and Manufacturing Performance: Organizational Logic and Flexible Production Systems in the World Auto Industry,' Industrial and Labor Relations Review, 48: 197-221.

Marchington, M, and Zagelmeyer, S. (2005) 'Forward: Linking HRM and Performance - A Never-Ending Search?’ Human Resource Management Journal, 15: 3-8.

Marlow, S. (2006) 'Human Resource Management in Smaller Firms: A Contradiction in Terms?' Human Resource Management Review, 16: 467-477.

Marsden, David. (1999). A Theory of Employment Systems: Micro-Foundations of Societal Diversity. Oxford: Oxford University Press. 
Orlitzky, M., and Frenkel, S. (2005) 'Alternative Pathways to High-Performance Workplaces,' International Journal of Human Resource Management,16: 1325 $-1348$.

Osterman, P. (1987). 'Choice of Employment Systems in Internal Labor Markets,' Industrial Relations, 26: 46-67.

Pfeffer, J. (1998) The Human Equation. Boston, MA: Harvard University Business School Press.

Purcell, J., and Kinnie, N. (2007) ‘HRM and Business Performance.’ In Boxall, P., Purcell, J., and P. Wright (eds), Oxford Handbook of Human Resource Management. Oxford: Oxford University Press, pp. 533-551.

Subramony, Mahesh. (2006) ‘Why Organizations Adopt Some Human Resource Management Practices and Reject Others: An Exploration of Rationales,' Human Resource Management, 45: 195-210.

Toh, S, Morgeson, F, and M. Campion. (2008) ‘Human Resource Configurations: Investigating Fit With the Organizational Context,' Journal of Applied Psychology, 93:864-82.

Verma, Anil. (2007) 'What Do Unions Do in the Workplace: Union Effects on Management and HRM Policies.' In Bennett, J., and B. Kaufman (eds), What Do Unions Do? A Twenty Year Perspective. New Brunswick: Transactions Press, pp. 275-312.

Wall, T., and S. Wood, S. (2005) 'The Romance of Human Resource Management and Business Performance, and the Case for Big Science,' Human Relations, 58: $429-61$. 
Wasti, S., Poell, R., and D. Çakar. (2008) 'Oceans and Notions Apart? An Analysis of the US and European Human Resource Development Literature,' International Journal of Human Resource Management, 19: 2155-2170.

Wright, Dunford, B., and Snell, S. (2001) 'Human Resources and the Resource Based View of the Firm,' Journal of Management, 27: 701-721.

Wright, P., Snell, S, and Dyer, L. (2005) 'New Models of Strategic HRM in a Global Context,' International Journal of Human Resource Management, 16: 875-881. 
Figure 1. Frequency Distribution of HRM Practices and Expenditures Per Capita



Panel (a)

Source: (Freeman and Rogers 1999: 124)

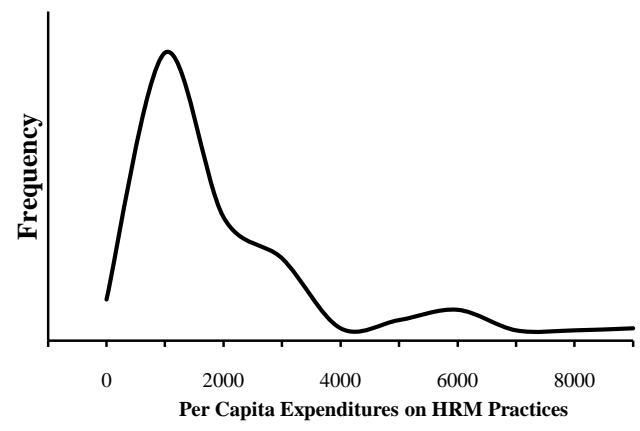

Panel (b)

Source: (Bureau of National Affairs 2006)

Figure 2. The HRM Demand Curve

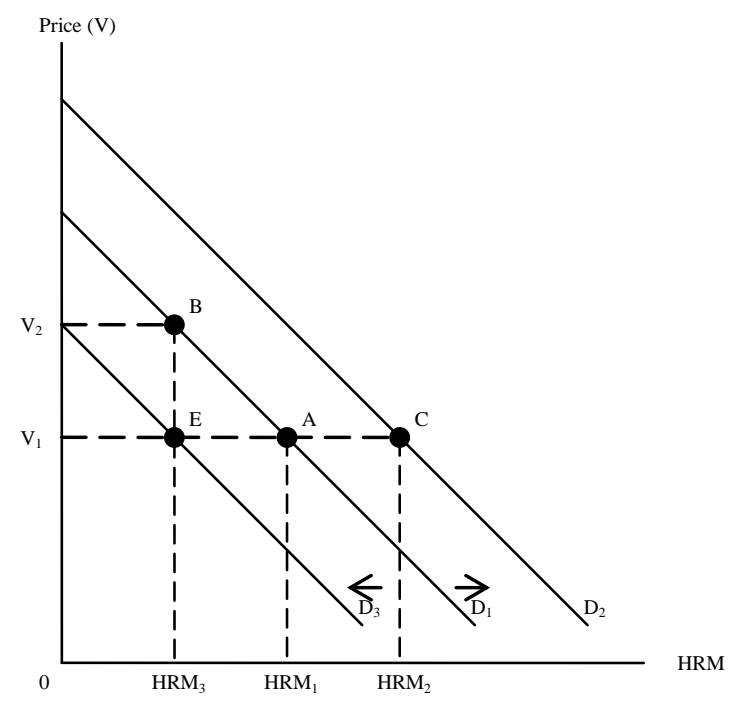

